\title{
FORMAÇÃO DO TÉCNICO AGRICOLA NO BRASIL: DESAFIOS E PERSPECTIVAS
}

\author{
M. A. CARVALHO ${ }^{1}$, M. E. F. CARNEIRO ${ }^{2}$, L. A. da S. SANTIAGO 3 , L. H. R. AFONSO \\ Instituto Federal de Educação, Ciência e Tecnologia Goiano \\ marco.carvalho@ifgoiano.edu.br ${ }^{1}$
}

Submetido 16/07/2015 - Aceito 29/04/2020

DOI: $10.15628 /$ holos.2020.3226

\section{RESUMO}

O Ensino Agropecuário ministrado no Instituto Federal Goiano Campus Ceres constituiu-se no cerne de nossa reflexão, tendo por interrogações os desafios e perspectivas de qualificação do técnico agrícola decorrente das políticas públicas de Educação Profissional Técnica e Tecnológica no Brasil (EPTT) - e como referência as diretrizes formativas emanadas pelas distintas legislações em três períodos, sejam, anterior ao Decreto 2.208/1997, para o presente trabalho denominado Escola Fazenda, na vigência da mencionada legislação e a partir de sua substituição pelo Decreto 5.154/2004. A problemática que orientou as análises relaciona-se às mudanças de diretrizes na EPTT e seus impactos no perfil de formação do técnico agrícola. Objetivamos interpretar e analisar a realidade e as contradições dessa formação recebida e recorremos aos elementos conceituais educação e trabalho, sob o prisma do materialismo histórico-dialético, como fundamentos teórico-metodológicos. Selecionamos como amostra os egressos no período de dez anos de 1997 a 2007. Constatamos que o curso, para os egressos, foi um facilitador para a empregabilidade em diversos segmentos do mercado e para acesso ao ensino superior.

PALAVRAS-CHAVE: Educação profissional, Mundo do trabalho, Técnico Agrícola.

\section{TRAINING OF THE AGRICULTURAL TECHNICIAN IN BRAZIL: CHALLENGES AND PROSPECTS}

\begin{abstract}
The Agricultural Education taught at the Goiano Federal Institute - Ceres Campus represented the core of our thinking, having by main issue the challenges and qualifying prospects of the agricultural technician, result of public policies on Professional Technical and Technological Education in Brazil (EPTT initials in portuguese) - having as reference training guidelines issued by the different legislations in three periods, either prior to the Decree 2,208/1997, for this study called Farm School, in the presence of the said law and from its replacement by Decree 5,154/2004. The issues that
\end{abstract}

guided the analysis is related to the changes in the EPTT guidelines and their impact on the training profile of the agricultural technician. We aim to interpret and analyze the reality and contradictions of the training received and appealed to the conceptual elements education and work through the prism of historical and dialectical materialism as theoretical and methodological foundations. We selected as sample graduates in ten years period from 1997 to 2007 . We noted that the course for the graduates was a facilitator for employability in various market segments and access to higher education.

KEYWORDS: Professional education, World of work, Agricultural Technician. 


\section{INTRODUÇÃO}

O objetivo da nossa pesquisa vem a ser uma reflexão acerca da importância do Ensino Agropecuário ministrado no Instituto Federal Goiano - IF Goiano, onde questionamos os desafios e possibilidades de qualificação, decorrentes das políticas públicas de Educação Profissional Técnica e Tecnológica no Brasil (EPTT), considerando as diretrizes advindas da Lei 9.394/1996 e os decretos 2.208/1997 e 5.154/2004, em vigência. A ênfase dada a esta análise recai sobre esse último decreto que propõe o perfil de formação integral do técnico agrícola sob as duas perspectivas delineadas a seguir. São elas, o perfil demandado pelo mercado, quando da elaboração de políticas educacionais de formação do referido profissional em termos de conhecimentos científicos, habilidades e experiência prática e o perfil desenhado de acordo com o ponto de vista do trabalhador, que percebe a qualificação como processo de apropriação dos conhecimentos socialmente produzidos, oportunizando-lhe melhores condições de vida, assim como lhe oportuniza a participação social e política enquanto cidadão.

\subsection{Teoria, contextualização e procedimentos}

A problemática que orientou as análises se relaciona às mudanças de diretrizes na EPTT e seus impactos no perfil de formação do técnico agrícola, objetivando conhecer, interpretar e analisar a realidade e as contradições da formação recebida pelo técnico agrícola, entre o proposto e o realizado, estabelecendo-se um recorte que compreende os egressos do referido curso, formados pelo Instituto Federal Goiano Campus Ceres no período de dez anos, de 1997 a 2007.

A preocupação com o embasamento teórico abrangeu uma retrospectiva da bibliografia específica do tema e uma pesquisa empírica sobre as percepções dos egressos quanto aos impactos das duas reformas educacionais1, na estrutura e operacionalização do curso analisado no período temporal mencionado.

Como instrumental teórico-metodológico, recorreu-se ao materialismo histórico-dialético, pertinente às estratégias de aproximação em relação ao referido objeto à luz das categorias trabalho, educação, ensino profissional e mudanças no mundo do trabalho.

No que se refere aos egressos, a partir de um universo de 929 diplomados em 10 anos, entre 1997 e 2007, foram analisados 108 questionários aplicados, representando 11,8\%, do universo de diplomados em cada ano analisado.

Os dados da pesquisa de campo passaram por análises das informações quali-quantitativas que forneceram resultados contraditórios, desde as descontinuidades até algumas interfaces entre as diretrizes da educação profissional nas três fases distintas2, assim como, as discrepâncias entre o proposto e o realizado, que explicitaram diferentes perfis de formação desse técnico agrícola, sua inserção e sua trajetória no mundo do trabalho.

\footnotetext{
${ }^{1}$ Decreto 2.208/1997 reestrutura a EPTT fundamentada na pedagogia das competências; Decreto 5.154/2004 substitui o decreto anterior e propõe a formação integral e omnilateral.

${ }^{2}$ As três fases mencionadas são o período Escola-Fazenda; Decreto 2.208/1997; e Decreto 5.154/2004.
} 
Acreditamos que, na perspectiva de análise apontada, se faz necessário que as categorias trabalho/educação sejam elementos centrais e explicativos do processo de formação e profissionalização, nesta pesquisa.

Tais categorias serão aqui tratadas, não de forma verticalizada, dado que as normas para elaboração desse artigo delimitam sua extensão, independentemente de sua complexidade.

\section{REVISÃO BIBLIOGRÁFICA}

\subsection{Trabalho Elemento Fundante da Humanização}

Segundo Marx \& Engels (1983), o que caracteriza o gênero humano e o diferencia dos outros animais é o trabalho, determinante em relação à capacidade humana de transformar a natureza e produzir os bens materiais e imateriais, necessários à sua vida e à reprodução da espécie. Quando eles, os homens, bancam a produção, ou seja, os seus meios de vida, esse fato é um passo adiante e é consequência de sua anatomia que se expressa em uma outra organização corporal.

Entendendo que o trabalho decorre da relação do homem com a natureza, Marx \& Engels (1983: 21), ao discutirem sobre o caráter ontológico e teleológico3 do trabalho, foram incisivos em afirmar que "o primeiro fato histórico é, portanto, a produção dos meios que permitam satisfazer essas necessidades, a produção da própria vida material”. Tal análise é pertinente como categoria para refletir sobre a educação profissional.

Marx e Engels trouxeram grande contribuição teórica para a discussão sobre o trabalho enquanto categoria de análise. Para a presente pesquisa, são particularmente importantes as análises marxianas4 relativas à divisão do trabalho e suas relações teleológicas em diferentes contextos e períodos históricos.

A produção dos meios de vida, para Costa (1996: 2), que se referencia em Marx, "é o dado primário, é a protoforma da atividade humana, que determina a forma humana de ser, o seu modo de vida, a sua organização social, a maneira como produz seu pensamento, suas ideias, representações, enfim, sua consciência". O homem é um ser genérico, porque tem características comuns estabelecidas e estas são ontológicas, próprias da hominização e humanização da espécie e do gênero.

\footnotetext{
3 Por caráter ontológico e teleológico do trabalho, reportamo-nos ao Dicionário de Filosofia de Nicola Abbagnano (2000). Por caráter ontológico do trabalho, entendemos que este está relacionado ao homem e seu desenvolvimento biológico, portanto, o trabalho "faz parte da ontogênese, ou seja, o desenvolvimento do indivíduo é uma breve repetição (recapitulação) da filogênese ou evolução da espécie a que pertence" (Abbagnano, 2000: 110). O caráter teleológico do trabalho indica sua finalidade, especificamente em relação ao trabalho, "a ação dessa causalidade, tal qual se admite no homem, pode não ser considerada diferente da ação da causalidade natural [...] [como no caso dos da abelha utilizada como exemplo por Marx], Objetivo e plano não são características da evolução orgânica e não constituem a chave para nenhuma de suas operações, mas são características da nova evolução [social e histórica] porque o homem tem objetivos e planos" (Abbagnano, 2000: 460).

4 Para esclarecer a distinção entre literatura marxista e marxiana, buscamos as definições de Enguita (1993: 170) ao discutir a relação homem/ambiente/práxis, assim como no capítulo sobre alienação, aponta como obra marxista aqueles textos elaborados à luz da produção intelectual de Karl Marx, tanto por seus seguidores, os marxistas, como até pelos não maxistas, mas simpatizantes, denominados marxizantes, assim como seus antagonistas, ou simplesmente anti-marxistas. Quanto aos escritos marxianos e as obras marxianas, tratam-se daqueles elaborados pelo próprio Marx ou em sua parceria, no caso de Engels.
} 
Ser humano, no sentido ontológico e que se relaciona com seu desenvolvimento biológico, assim como ao realizar ações que caracterizam sua humanização, que no sentido teleológico indica existência de uma finalidade previamente pensada, significa que tais ações, concretizadas no trabalho produzido pelo homem com finalidade objetiva, são ações pensada e planejada, que a relação entre os homens e a natureza nas atividades de produção de sua subsistência é produto de consciência prévia do trabalho produtivo. O que significa que as relações de produção são determinadas pelas relações estabelecidas no processo de trabalho, elemento fundante, característico do gênero humano.

Os animais não humanos estabelecem relações com a natureza aproveitando o que esta oferece e apresentam suas características genéticas como determinadas.

A natureza em grande parte [é]fixa e sua ação é semelhante, para não dizer idêntica aos outros membros de sua espécie. Seu relacionamento com o ambiente, com os membros da mesma espécie e outros animais obedecem às normas biologicamente estabelecidas, mais ou menos complexas, de agrupamento, convivência, acasalamento e reprodução. Sua ação é especializada e determinada por leis biológicas semelhantes na espécie e, em condições naturais, não apresentam diferenciação individual e são transmitidas aos seus descendentes através de carga genética. Seu ato não é voluntário, não apresenta consciência de finalidade, ou seja, uma ação produzida previamente como pensamento (Costa, 1996: 5).

No processo de trabalho e humanização, o homem cria os instrumentos necessários à relação homem/natureza, o que só é possível pelo desenvolvimento da finalidade, consciência e ação. $O$ processo de trabalho constitui-se numa relação dialética entre o homem e a natureza transformando-a, humanizando-a e, ao modificá-la, transforma-se a si próprio, produzindo e reproduzindo as características da espécie enquanto dotada de humanidade.

A consciência e a linguagem são também produto do trabalho no procedimento de hominização e de humanização, que é a protoforma do ser social. O trabalho é configuração/qualidade exclusivamente humana como ação transformadora consciente da Natureza.

O trabalho realizado/objetivado é o produto, mas nas sociedades desiguais ele é aviltado/desfigurado, pois não fica com quem o produziu, o trabalhador, uma vez que é apropriado pelo possuidor-proprietário. No sistema capitalista, os trabalhadores e capitalistas estão nos polos antagônicos do processo de produção e mantêm uma constante relação de conflito, pois o trabalhador vende a sua força de trabalho em troca de salário e o capitalista só compra a força de trabalho, porque ela é a única mercadoria que produz mais-valia apropriada, privadamente, pelo capitalista. O trabalho explorado e apropriado pelo possuidor-proprietário é resultado de uma relação social que se fundamenta na propriedade privada, na cisão da sociedade em classes antagônicas e resulta da exploração do trabalhador-produtor, logo, é um trabalho-estranhado.

O estranhamento separa o homem do produto de seu trabalho, de seu próprio ser e dos outros homens, criando contradições entre os que produzem e aqueles que dominam e se apropriam do produto do trabalho alheio. O trabalhador-produtor, ao ser expropriado, é aviltado materialmente e espiritualmente, consequentemente, se aliena. A objetivação é uma condição 
permanente do homem, mas a alienação é uma forma particular que se expressa em uma sociedade segundo as formas econômico-sociais historicamente determinadas.

O estranhamento é inerente às sociedades baseadas na propriedade privada e na divisão em classes sociais antagônicas, portanto, ação humana que pode ser modificada e superada na construção de outra sociedade.

\subsection{Profissionalização e Qualificação: exigência das sociedades complexas}

O ensino técnico profissionalizante da EPTT é uma das poucas opções educacionais que assume de forma clara a qualificação para o trabalho, tornando-se particularmente importante definir que profissionalização para o trabalho é esta na sociedade capitalista.

Bruno (1996: 91-92) conceitua qualificação "como um conjunto estruturado de elementos distintos e hierarquizados reciprocamente relacionados ... que decorre de relações sociais historicamente determinadas".

Neste estudo, interessa-nos interpretar a qualificação na organização de produção capitalista que Bruno (1996: 92) apresenta como a "capacidade de realização das tarefas requeridas pela tecnologia capitalista" que, historicamente, tem utilizado a capacidade quer muscular, quer intelectual, que tem sido conjugada de diferentes formas de combinação na diversidade do processo de trabalho.

Faz sentido para Bruno (1996: 92) pontuar que "é qualificada aquela força de trabalho capaz de realizar as tarefas decorrentes de determinado patamar tecnológico e de uma forma de organização do processo de trabalho". Não podemos nos esquecer de que são agregados, constantemente, novos requisitos.

Desde 1970, marco da Terceira Revolução Industrial, a produção capitalista mudou o foco de exploração da força de trabalho de braçal para intelectual, a qual vem assumindo cada vez mais importância, evidenciando a necessidade de uma qualificação via educação, formal e informal, com a exigência de patamares cada vez mais altos de escolarização e certificação formal, sendo o Ensino Médio - EM, quer propedêutico quer profissionalizante, indispensável para a empregabilidade.

Tais exigências do mercado, de patamar mínimo de escolaridade como o EM, devem-se à transformação produtiva, que compõe a Terceira Revolução Industrial, que vem ocorrendo nos países industrializados e se impondo à economia internacional. Sua base está no conhecimento científico e tecnológico, centrado na informação e na informática, em novos materiais, novos processos, na biotecnologia, na microeletrônica, nas novas formas de organização do trabalho e também na nova pedagogia do capital que, aparentemente, avança de uma perspectiva taylorista/fordista para a toyotista na era das tecnologias da informação e comunicação - TIC's.

À medida que as técnicas utilizadas na produção vão desenvolvendo-se e tornando-se mais complexas, exigindo um volume de conhecimentos mais abrangente, nasce, concomitantemente, uma outra forma de qualificação para o trabalho, vinda de fora do processo produtivo, via educação técnica, mas que permanece ligada a esse processo pelas relações que estabelece com o mercado de trabalho. Essa educação, segundo Enguita (1993), como o processo de conversão do 
trabalho simples em trabalho complexo, ou de qualificação do trabalho em geral, produz uma força de trabalho capaz de gerar um valor de troca maior no mesmo espaço de tempo.

O fato de a força de trabalho ser a única mercadoria capaz de produzir mais valor do que ela própria contém torna a qualificação do trabalhador uma questão central e determinante para o aumento da produção e, consequentemente, acúmulo de riquezas.

Temos que considerar que, nas sociedades complexas como a nossa, os sujeitos sociais têm que ser preparados para a participação econômica/trabalho, social e política e para isso têm que ter acesso a condições de apropriação dos conhecimentos científicos e tecnológicos socialmente produzidos. Nessa realidade, a educação tem assumido centralidade e importância cada vez maior para se concorrer no mercado de trabalho.

Tal importância e centralidade da educação, como afirma Bruno (1996: 96), decorrem também do deslocamento da exploração do componente manual para o intelectual, modificandose, também, as formas de disciplina e de controle da força de trabalho. Sendo o cérebro do trabalhador, ou seja, sua capacidade de raciocínio e sua estrutura psíquica, o elemento a ser explorado no processo de trabalho, as técnicas de controle e disciplina convencionais, que incidiam primordialmente sobre o corpo do trabalhador, estão sendo substituídas pelas técnicas gerenciais participativas. Tais técnicas apresentam grande carga simbólica que têm dupla função: a de se transformar em canais formais de apropriação da capacidade de raciocínio dos trabalhadores e a de controlar e disciplinar a estrutura psíquica, já que responsabilidade, envolvimento, interesse pelo trabalho e capacidade de inovar são, hoje, importantes fatores de produção.

Podemos constatar que, com a complexificação do processo de organização da produção e divisão social do trabalho, a educação passa a ter caráter obrigatório na sociabilização dos trabalhadores, com a função de difundir o disciplinamento e a instrução geral da força de trabalho no capitalismo em conformidade com as classes sociais na perspectiva histórica de cada sociedade. Portanto educar é preparar para o trabalho.

\subsection{Educação e Trabalho}

Cabe observar que a educação é um fenômeno complexo da existência humana. Por conseguinte, também tem muitas definições, compreensões ou explicações e acontece em diferentes lugares, de diversos modos, conforme nos aponta Saviani (1991: 22-23):

A educação pode ser conceituada como um fenômeno próprio dos seres humanos e é ao mesmo tempo uma exigência do processo de trabalho e para o trabalho, assim como é, igualmente, um processo de trabalho enquanto uma ação individual. (...). Para produzir materialmente necessário se faz ao homem antecipar em ideias os objetivos de sua ação consciente, o que inclui os aspectos relacionados às técnicas, à ciência e à arte, o dito trabalho não material. Obviamente a educação se situa nessa categoria.

O ensino profissional, como qualquer espaço da sociedade capitalista, faz-se em um processo de conflitos, entre a formação pura e simples para o mercado e a luta dos trabalhadores pela apropriação dos conhecimentos socialmente produzidos como instrumento de participação 
política e melhor qualidade de vida. "Os bens e serviços resultantes do processo de trabalho não são mais do que veiculadores de valores de troca produzidos no âmbito dessas relações" (BRUNO, 1996: 95). Portanto, o trabalho, no capitalismo, não é só uma relação constituída entre o sujeito/força de trabalho e o objeto/produto é, sobretudo, produção de valores de troca. 0 aumento da qualificação da força de trabalho para o capital tem por objetivo primeiro o aumento da produtividade do trabalho, o que significa dizer produção de mais trabalho em menor tempo, o que significa maior possibilidade de expropriação de mais valia.

Pelo trabalho, segundo Marx \& Engel (1983), o homem desenvolve seu processo de humanização e conscientização, visto que ele está, intencionalmente, e de forma planejada, antecipadamente, produzindo sua vida material. Isso permite admitir o caráter teleológico do trabalho, pois, segundo os mesmos autores, trata-se de um ato consciente, previamente articulado mentalmente e, particularmente, com finalidade específica.

O trabalho é o único ponto no qual se demonstra ontologicamente uma finalidade, passando a ser um ato real e materialmente efetivo.

A EPTT nasce no trabalho em decorrência das relações capitalistas de produção que a engendram e que concebem a qualificação da força de trabalho, via educação, como educação para o trabalho. $O$ ensino profissionalizante tem como objetivos específicos qualificar e habilitar para a aquisição de técnicas apropriadas ao desenvolvimento de um tipo específico de trabalho ou de ocupação, em uma área profissional e no mercado. As diversas qualificações dizem respeito à divisão social do trabalho em braçal e intelectual:

A divisão do trabalho em uma nação obriga, em primeiro lugar, à separação entre o trabalho industrial e comercial e o trabalho agrícola; e, como consequência, à separação entre cidade e o campo e à oposição dos seus interesses. (...). A posição de quaisquer destas subdivisões particulares relativamente a outras é condicionada pelo modo de exploração do trabalho agrícola, industrial e comercial [patriarcado, escravatura, ordens e classes] (Marx \& Engels, 1983: 20).

É necessário que se exponha, segundo Marx \& Engels (1983), que a educação traz consigo os pensamentos da classe dominante, pois estes são e foram iguais em diferentes épocas, o que é decorrência da posse dos meios materiais e do poder de que esta classe se apropria, em determinados períodos e sociedades. A educação/preparação, ainda que qualifiquem a força de trabalho para produção de valores de uso, para Enguita (1993: 177) "constitui o conteúdo material da riqueza, seja qual for a forma social dela. Na sociedade capitalista, os valores de uso são, além disso, portadores do valor de troca".

De uma maneira geral, mas particularmente, no caso do objeto de estudo da presente pesquisa, o ensino agrícola forma técnicos para trabalhar no setor da economia que é subsumido pelos setores industrial, comercial e financeiro, A montante das unidades de produção agrícola, em que as organizações empresariais fornecedoras de insumos diversos possuem estrutura de 
oligopólio5 produtivos, no caso de máquinas, equipamentos, adubos e defensivos, dentre outros, assim como a montante do capital financeiro/bancário que dita as regras do jogo no financiamento de custeio dos insumos utilizados na agricultura e pecuária, cujos preços para aquisição, em geral tabelados, propiciam trocas desiguais (Além, 2010).

Igualmente, a jusante das unidades produtivas em relação às indústrias de processamento, estruturas de apoio logístico e de exportação, o caráter oligopolizado tem no capital financeiro o pano de fundo de suas diretrizes operacionais.

O agronegócio embora sendo um setor importante da economia brasileira, abarcando $23 \%$ do PIB e respondendo por $43 \%$ de todos os empregos do país e aproximadamente $39 \%$ das exportações, transfere capital para os outros setores da economia6. A profissionalização da força de trabalho para este setor tem que levar em consideração a realidade acima apontada, pois o agronegócio é atividade de capital intensivo, de pesquisa e de adoção crescente de novas tecnologias e vem exigindo novos e maiores patamares de educação.

Constatamos que a qualificação da força de trabalho para agricultura e pecuária do agronegócio, como nos demais setores da economia à medida que os conhecimentos científicos, as técnicas, tecnologias utilizadas na produção, vão tornando-se complexos, demandam cada vez mais conhecimentos abrangentes e verticalizados.

Nessa perspectiva, mediante a formação profissional, desde o Decreto 5.154/2005, existe a possibilidade de se resgatar a base unitária de formação no ensino médio quando se restabelecem as condições jurídicas, políticas e institucionais que assegurem a "consolidação da formação básica unitária e politécnica, centrada no trabalho, na ciência e na cultura, numa relação mediada com a formação profissional específica que se consolida em outros níveis e modalidades de ensino" (Frigotto, Ciavatta \& Ramos, 2005: 43).

Considerando os elementos conceituais e categorias teóricas aqui trabalhadas, acredita-se que seja possível analisar criticamente as possibilidades de formação do técnico em agropecuária à luz da nova configuração do mundo do trabalho, das demandas de mercado. Mesmo sabendo que a qualificação dessa força é uma exigência do capital, mas é também um direito do trabalhador buscar, das mais variadas formas, principalmente via educação, o acesso ao saber universalmente edificado, maneiras de se qualificar para ocupar postos de trabalho que lhe propicie melhor remuneração, melhores condições de vida e a construção de sua cidadania.

\footnotetext{
${ }^{5}$ Segundo Além (2010), oligopólio corresponde a uma estrutura de mercado de concorrência imperfeita, na qual o mercado é controlado por um número reduzido de empresas, de tal forma que cada uma tem que se submeter aos comportamentos e às reações das outras quando toma decisões de mercado. No oligopólio, os bens produzidos podem ser homogêneos ou apresentar alguma diferenciação sendo que, geralmente, a concorrência efetua-se mais ao nível de fatores, como a qualidade, o serviço pós-venda, a fidelização ou a imagem e não tanto ao nível do preço.
}

${ }^{6}$ Fonte: Disponível em http://www.ecoagro.agr.br/agronegocio-brasil. Acessado em 11 de julho de 2014. 


\section{RESULTADOS E DISCUSSÕES}

\subsection{O perfil do Técnico Agrícola formado pelo IF Goiano Campus Ceres}

$\mathrm{Na}$ trajetória da educação profissional agrícola brasileira, em diversas fases, as políticas públicas foram implantadas com o intuito de formar técnicos para atender aos interesses hegemônicos, mais como política de Governo que propriamente política de Estado.

Desde o final do século XIX e no transcorrer do século XX o ensino profissional no Brasil, particularmente o ensino técnico operacional, teve como um de seus objetivos formais precípuos e reincidentes a formação de jovens de origem humilde, inclusive filhos de pequenos agricultores e/ou agregados, para o mercado de trabalho. Cabe apontar que tais políticas têm sido marcadas por conflitos e descontinuidades inerentes ao jogo de forças políticas, no qual, de um lado, os trabalhadores lutam por um ensino que os profissionalize, mas que também seja instrumento de luta política por melhor qualidade de vida e, do outro lado, a elite busca profissionalizar unicamente para atender aos atributos exigidos pelo mercado, conforme pode ser observado no próprio texto de criação da Escola de Aprendizes e Artífices7.

Especificamente em relação ao ensino técnico agrícola, desde então ele tem passado por diversas fases e transformações decorrentes de políticas públicas que ora valoriza, ora desvaloriza a formação desse profissional, em geral em conformidade com demandas do mercado de trabalho que ora exige habilidades técnicas, ora operacionais, sempre à luz das diretrizes estruturantes da economia mundial.

No que tange à formação recebida e ao processo de enfrentamento da realidade no mundo do trabalho, pode ser observado que, com base nas informações da Tabela 1, a formação integral recebida e os conhecimentos e habilidades por ela proporcionadas foram fatores de sucesso, apontados pelos informantes de todas as fases, como o que mais impactou positivamente sua realidade atual. A avaliação dos informantes refletiu diretamente em suas análises sobre as outras categorias da tabela em questão.

Considerando as diretrizes educacionais mais recentes, que são objetos de nossa análise, ao estudar o perfil do egresso do Curso Técnico Agrícola do Instituto Federal Goiano Campus Ceres, no interregno de 1997 a 2007, à luz da Tabela 1, constatou-se uma correlação positiva entre formação recebida e exigências do mundo do trabalho. Podemos estabelecer inferências, à luz das informações dadas pelos egressos, de que o tipo e metodologia de ensino, o conhecimento técnico-científico, a qualidade do processo didático-pedagógico, associados ao fato de que na rede federal de EPTT, segundo Carvalho \& Carneiro (2012), é insignificante a presença de professores leigos, profissionais da educação estes, que em sua maioria, possuem significativa titularidade

\footnotetext{
${ }^{7}$ Em execução da Lei n. 1.606, de 29 de dezembro de 1906 e Decreto 7.566, de 23 de setembro de 1909: Considerando: que o argumento constante da população das cidades exige que se facilitem às classes proletárias os meios de vencer as dificuldades sempre crescentes da luta pela existência: que para isso se torna necessário, não só habilitar os filhos dos desfavorecidos da fortuna com o indispensável preparo técnico e intelectual, como fazê-los adquirir hábitos de trabalho profícuo, que os afastara da ociosidade ignorante, escola do vício e do crime; que é um dos primeiros deveres do Governo da República formar cidadãos úteis à Nação (Brasil, 1909).
} 
acadêmica, corroborando e contribuem para uma sólida formação teórica e prática desse profissional.

Novamente nos reportamos à questão da cultura institucional e sua influência na formação dos alunos, independentemente da diretriz pedagógica/legal vigente, para justificar que, mesmo com as mudanças dos instrumentos legais, a formação recebida e a estrutura montada na década de 1990, sob a orientação do Modelo Escola-Fazenda, é que realmente fez a diferença na formação do técnico agrícola analisado.

Tabela 01 - Influência da formação recebida e a realidade no mundo do trabalho, nas três fases

\begin{tabular}{c|cc|ccc}
\hline Categoria & Item & Escola Fazenda & Decreto 2208 & $\begin{array}{c}\text { Decreto } \\
5154\end{array}$ \\
\hline \multirow{4}{*}{ Formação/Trabalho } & F.I. & 35,7 & 30 & 37,5 \\
& C.H.S. & 28,6 & 20 & 37,5 \\
& Post. & 10,7 & 20 & 0 \\
& f mercado & 10,7 & 10 & 25 \\
& fgraduação & 14,3 & 20 & 0 \\
& Currículo & 0,0 & 0 & 0 \\
\hline
\end{tabular}

Legenda: F.I. (Formação Integral recebida); C.H.S. (Conhecimentos e habilidades na solução de problemas no campo profissional); Post. (postura profissional e ética proporcionada); $\neq$ mercado (Diferencial facilitou ingresso no mercado); \# graduação (diferencial facilitou formação superior); Currículo (Curso tem bom nome e facilita seleção de currículo). Fonte: Carvalho (2015)

Além disso, conforme pode ser observado no Gráfico 1, a convivência com perfis de professores e alunos de origens distintas influenciou positivamente em grande medida segundo egressos informantes, no desenvolvimento de um perfil cidadão do mundo, seja em agronegócio, na agricultura familiar o seja em outros ramos, visto que tal formação integral foi e continua a ser importante fator para enfrentar-se o mercado em melhores condições e para assegurar a sobrevivência.

Dentre as razões que apontou como justificativa para tal relevância da formação recebida, $66 \%$ apontou que a troca de experiência favorece o amadurecimento, assim como favorece a autonomia para outros $17 \%$.

Além de verificar o nível de influência do curso na formação cidadã, quando indagados sobre as razões de seu sucesso, houve igualmente predominância ao apontarem que o ambiente favorece o amadurecimento, assim como aspectos de exercício de liderança e trabalho de equipe e postura de TA adquirida. Lembrando que o público alvo precípuo das instituições federais de ensino profissional de nível técnico é composto por jovens a partir de 14 anos e que ainda não se inseriram no mundo do trabalho, exceto na condição de auxiliares de seus pais.

Muitas têm sido as análises relativas aos desafios no âmbito do processo de institucionalização dos Institutos Federais de Educação, Ciências e Tecnologia - IF's, que se encontram em plena fase de estruturação e, ao mesmo tempo, em expansão, em que a interiorização e verticalização são tidos como um dos aspectos mais controvertidos. 
Gráfico 1 - Influência do curso na vida pessoal e profissional - 1997 a 2007

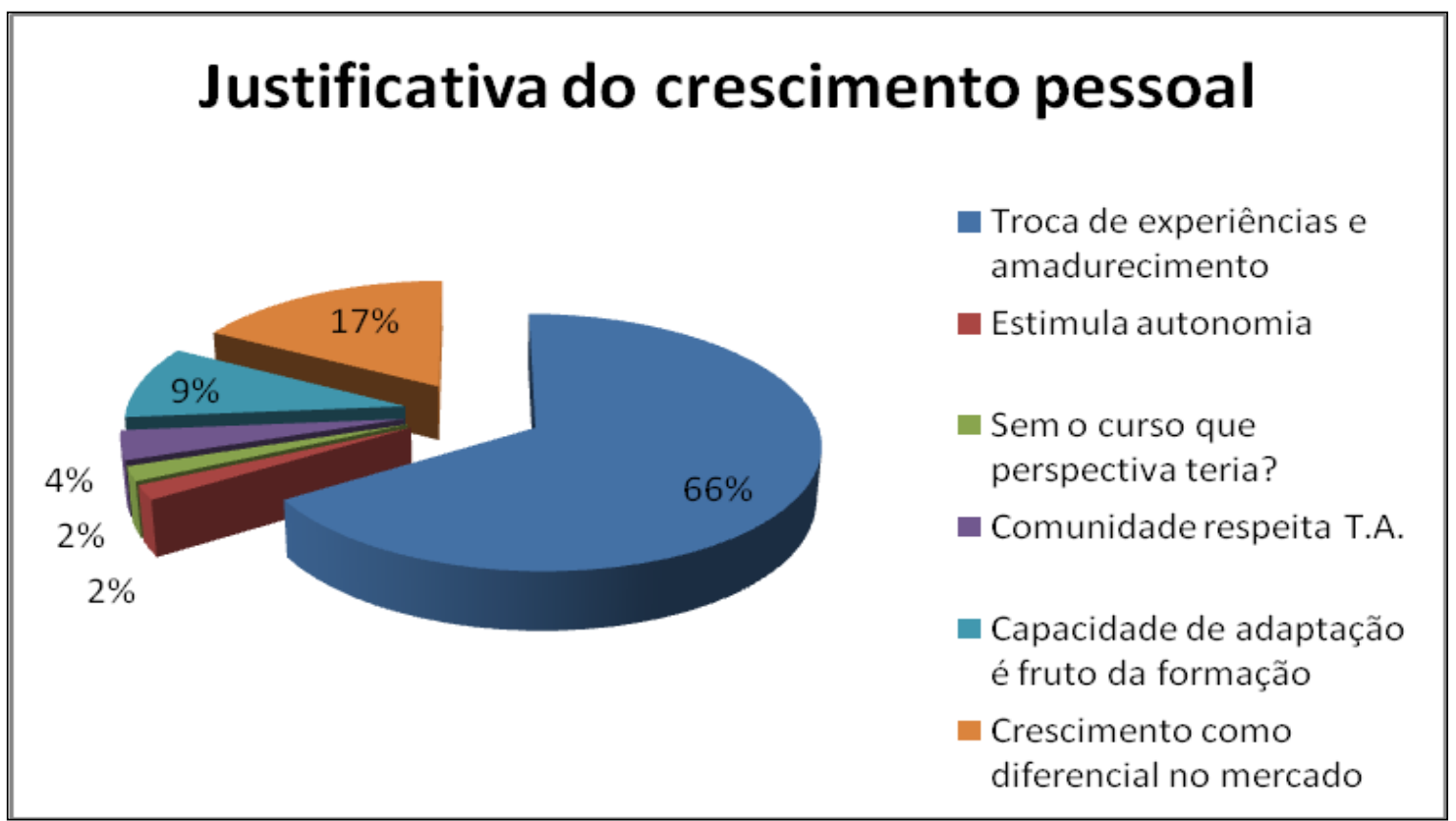

Fonte: Carvalho (2015)

A discussão acadêmica traz a pauta dilemas e conflitos inerentes a tais mudanças, sejam elas físicas, tecnológicas, culturais e institucionais, como pode ser observado em Souza \& Castioni (2012) e, especificamente, em estudos de Ficher \& Waiandt (2012: 88), que discutem a educação profissional e os desafios do desenvolvimento brasileiro. Eles propõem a integração entre a pósgraduação, a educação básica e os mundos do trabalho, isso feito a partir da "construção de um eixo formativo que se inicia na educação básica e pode evoluir até o doutorado para profissionais".

Assim, as análises devem ir além da questão formal, pois as mudanças efetivas não ocorrem por decreto e exige um movimento que requer uma vontade coletiva, a mencionada intervenção consciente, em torno de um projeto de escola compatível com as necessidades e exigências imprescindíveis ao desenvolvimento das forças produtivas e da ciência, aproximando-se, assim, da escola politécnica.

\section{CONSIDERAÇÕES FINAIS}

Mesmo que o perfil de formação recebido e apontado pelos egressos informantes, nas três fases e períodos analisados, Escola Fazenda (1997 a 1999), Pedagogia das Competências (2000 a 2006) e Formação Unitária (2007), apontem que nas distintas fases facultam à formação integral e cidadã, não é possível atribuir tais resultados apenas e simplesmente como produtos e reflexos do Decreto 5.154/04, que propõe a formação omnilateral, o que requer maior esforço investigativo.

Entretanto é possível, à luz das análises, fazer inferências de que a formação unitária e omnilateral estiveram de alguma forma, presentes nas três fases, conforme apreciação valorativa dos egressos informantes. Isso nos oferece elementos para afirmar, segundo Carvalho; Carneiro 
(2012) que a cultura escolar das escolas agrotécnicas e sua comunidade interna, e não as legislações, é que efetivamente deram os contornos formativos a esse técnico, mesmo porque, os pesquisadores assumem que a efetividade da consecução ou não dos propósitos não acontecem por decreto, mas requerem uma vontade coletiva.

Nesse sentido, há que se considerar que as mudanças recentes em relação às diretrizes institucionais do ensino profissional, particularmente o Instituto Goiano e o Campus Ceres, com destaque, no caso, dos novos papeis assumidos pelos Institutos Federais, decorrentes da Lei $11.892 / 2008$, que tem tido dentre os obstáculos à sua institucionalização, a reconfiguração de sua própria identidade cultural histórica, o que se acredita não ser diferente em relação aos demais Institutos Federais.

Em relação ao perfil do egresso, particularmente em relação ao curso e à Instituição pesquisada, a intervenção da comunidade acadêmica e local, "de forma consciente ou não", possibilitou ao IF Goiano Campus Ceres enfrentar as reformas que fizeram parte de sua história institucional. Tais reformas, seja no período Escola-Fazenda, Pedagogia das Competências ou Unitária, facultou com que fosse preservado o compromisso com a qualidade do curso técnico, como ficou explicitado pelos egressos em seus apontamentos. Ademais, para que tais informações fossem referendadas, a partir dos dados da pesquisa de Carvalho \& Carneiro (2012), constatamos maior empregabilidade em diversos segmentos do mercado, seja na agricultura familiar, na média e grande propriedade, assim como no contexto das atividades dos diversos ramos do agronegócio que, igualmente, apontaram a formação recebida como fator facilitador de acesso e desempenho em cursos superiores, sejam eles na área agrícola, ou em outras, de formação profissional.

\section{REFERÊNCIAS BIBLIOGRÁFICAS}

Abbagnano, N. (2000). Dicionário de filosofia. São Paulo: Martins Fontes.

Além, A. C. (2010). Macroeconomia: Teoria e prática no Brasil. São Paulo: Campus.

Brasil. MEC. (1909). Decreto no 7.566, de 23 de setembro de 1909. Créa nas capitaes dos Estados Escolas de Aprendizes Artífices, para o ensino profissional primario e gratuito. Extraído de http://portal.mec.gov.br/setec/arquivos/pdf3/decreto_7566_1909.pdf. Acesso em 30 de maio de 2015.

Bruno, L. (1996). Educação, qualificação e desenvolvimento econômico. In: Bruno, L. (org.). Educação e trabalho no capitalismo contemporâneo: leituras selecionadas (pp. 91-123). São Paulo: Atlas.

Carvalho, M. A. (2015). Técnico agrícola no Brasil: entre o proposto e o real. Curitiba: Appris.

Carvalho, M. A; Carneiro, M. E. F. (2012). Ensino técnico agrícola: espaço de conflitos, descontinuidades e contradições. Anais III SENEPT 2012. Belo Horizonte, CEFET Minas.

Costa, S. (1996). O trabalho como elemento fundante da humanização. Revista Estudos, Goiânia, UCG, v. 22, n. 3 e 4, 171-188. 
Enguita, M. F. (1993). Trabalho, escola e ideologia: Marx e a crítica da educação. Tradução Ernani Rosa. Porto Alegre: Artes Médicas.

Fischer, T; Waiandt, C. A. (2012). Educação profissional e os desafios do desenvolvimento brasileiro: uma proposta integradora entre a pós-graduação, a educação básica e os mundos do trabalho. Revista Brasileira de Pós-Graduação, Brasília, CAPES, v. 9, no 16, 84-111.

Frigotto, G.; Ciavatta, M.; Ramos, M. (2005). Ensino médio integrado: concepções e contradições. São Paulo: Cortez.

Marx, K.; Engels, F. (1983). A ideologia alemã: crítica da filosofia alemã mais recente na pessoa dos seus representantes Feuerbach, B. Bauer e Stirner, e do socialismo alemão da dos seus diferentes profetas. V.I, 4. ed. São Paulo: Martins Fontes.

Saviani, D. (1991). Pedagogia histórico-crítica: primeiras aproximações. Polêmicas do nosso tempo. São Paulo: Cortez.

Souza, E. C. L de; Castioni, R. (2012). Institutos Federais: os desafios da institucionalização. Brasília: UNB. 